\title{
Communication in Multilateral Bargaining*
}

\author{
Marina Agranov ${ }^{\dagger} \quad$ Chloe Tergiman \\ Caltech UBC
}

September 2013

\begin{abstract}
One of the most robust phenomena in the experimental literature on multilateral bargaining is the failure of proposers to extract equilibrium rents. However, all previous experiments have overlooked the fact that outside the lab committee members are allowed to - and do - engage in sometimes intense communication processes prior to voting on a proposal. We conduct an experimental test of the Baron-Ferejohn model in which we allow committee members to engage in unrestricted cheap-talk communication before a proposal is submitted. We find that proposers extract a significantly higher share of resources when communication is allowed. Communication increases proposer power through two channels. First, it mitigates the uncertainty surrounding the amount a coalition member is willing to accept. Second, it allows potential coalition members to compete for a place in the coalition by lowering this stated price.
\end{abstract}

*The authors would like to acknowledge generous support from SSHRC IDG grant \#F12-00384 as well as the Gordon and Betty Moore Foundation Grant GBMF\#1158: Experimentation with Large, Diverse and Interconnected Socio-Economic System. We would also like to thank Ernesto Dal Bo, Pedro Dal Bo, Timothy Feddersen, Guillaume Frechette, Alessandro Lizerri, John Ledyard, Rebecca Morton, Muriel Niederle, Salvatore Nunnari, Erkut Ozbay, Thomas Palfrey, Al Roth, Emanuel Vespa, Alistair Wilson, Leeat Yariv, the seminar participants at Caltech, UBC, Stanford and UCSD, the conference participants at ESA (Tucson and New York), SITE, and Public Choice for helpful comments and discussions.

${ }^{\dagger}$ California Institute of Technology, MC 228-77, Pasadena, CA 91125 USA. magranov@hss.caltech.edu

${ }^{\ddagger}$ Corresponding author: University of British Columbia, 2053 Main Mall, Vancouver BC V6T1Z2, Canada. chloe.tergiman@sauder.ubc.ca, +1 (778) 986-9473. 


\section{Introduction}

One of the primary duties of legislatures is the appropriation of government funds. The appropriations committee is one of the most powerful Senate committees and its head is typically able to steer a disproportionate amount of funds to his district. ${ }^{1}$ Given the enormous impact that such decisions have, it is no surprise that a large body of empirical as well as theoretical work has aimed at understanding the legislative process and the bargaining power held by those who propose bills.

Theoretically, there has been large progress in understanding proposer power. BaronFerejohn (1989) is the most widely used model of multilateral legislative bargaining. In this framework, a proposer is chosen according to a rule, and proposes a particular budget split. Voters face a tradeoff between supporting a bill from which they would receive a particular amount versus voting against it and going through another round of legislative bargaining, with a possibly different proposer who wouldn't necessarily include them in the coalition, and a smaller-sized pie to split. The proposer takes advantage of this uncertainty about the future and can extract large rents from the voters whose continuation values are the lowest. ${ }^{2}$

Yet, while theoretical models on legislative bargaining have long been able to capture the advantages of leading a bill to the floor, laboratory experiments have not been able to match this stylized fact. ${ }^{3}$ In fact, the under-exploitation of proposal power is a robust experimental finding. Being able to match this fundamental theoretical prediction is of paramount importance if one is to then use the laboratory to explore legislative bargaining further.

While the legislative process is highly complex and impossible to replicate in a theory or in the laboratory, one important aspect of legislative bargaining that has been ignored

\footnotetext{
${ }^{1}$ One recent example is that of Ted Stevens from Alaska. See http://www.cepr.net/err/nytimesarticles/call_pork_11_29.htm

${ }^{2}$ Theoretical extensions include (but are not limited to) Eraslan and Merlo (2002) who shows uniqueness of the stationary equilibrium; Banks and Duggan (2000) who generalize this model to multidimensional choice space; Diermeier and Merlo (2000) who study a dynamic model of government formation in Parliamentary democracies and Battaglini and Coate $(2007,2008)$ investigate the dynamic model of public spending; Diermeier and Feddersen (1998) who study cohesion in legislatures and the vote of confidence procedure; Tergiman (2013) who adds to that the possibility of offering a public good; Battaglini, Nunnari and Palfrey (2011) who study a version of the Baron-Ferejohn model in which the current decision becomes the status quo in the next period.

${ }^{3}$ In most experiments, proposers do obtain higher shares than the coalition partners, but the difference is very far from what is predicted by the theory. We discuss this in more detail below.
} 
in experiments is the issue of negotiations and communications. ${ }^{4}$ Indeed, in legislatures, appropriation bills reach the floor only after extensive negotiations and back-room deals. Negotiations are an integral part of the bargaining process and members of the legislature spend a considerable amount of time and resources communicating with each other in order to reach an agreement before bringing the bill to a vote.

In this paper we show that the addition of a cheap-talk communication stage allows legislative bargaining laboratory experiments to be largely reconciled with the theory, an outcome that has eluded experiments for over two decades. ${ }^{5}$ This happens via two channels: (1) communication serves as a tool for proposers to learn other members' reservation prices and (2) communication is a way for members to convince the proposer to add them to the coalition by competing and lowering their price. In other words, communication mitigates the uncertainty around the voting behavior of potential coalition partners and makes the competition between coalition partners more intense. This enhances the ability of the proposer to exploit his proposal power and get shares close to those predicted by the theory.

Experiments provide a direct and powerful tool for investigating the effect communication on bargaining process. One of the advantages of the laboratory experiments is that we are able to create a controlled environment in which the only difference between treatments is the ability of legislators to negotiate with one another before the proposal reaches the floor.

There have been numerous experiments that have aimed at testing the Baron-Ferejohn model, though none have incorporated a communication stage. Generally, the laboratory results match several features of the Baron-Ferejohn model. In particular, delays because of proposals being turned down are rare, and in most proposals offers are made to half the members of the legislature (so as to receive a strict majority of votes but no more than needed). Regarding proposer power, none of the laboratory experiments come close to capturing its magnitude. In some studies, such as Deirmeier and Morton (2005), proposer power is close to inexistent, though this unusual result may be due to the procedures and small number of observations in the experiments that were conducted. In others such as Frechette, Kagel and Morelli (2005(a), 2005(b)) as well as in Frechette, Kagel and Lehrer (2003), and more recently Drouvelis, Montero and Sefton (2010), Kagel, Sung and

\footnotetext{
${ }^{4}$ The Baron-Ferejohn model of legislative bargaining is silent on the presence of communication: rational agents should not need to communicate as all continuation values in a game are calculable.

${ }^{5}$ Indeed, the first test of Baron-Ferejohn dates back to McKelvey (1991).
} 
Winter (2010), Battaglini, Nunnari and Palfrey (2012), Tergiman (2012) and Miller and Vanberg (2013), proposers receive higher shares than the other members of the coalition, but these shares remain far below what is predicted by the theory.

While our paper is the first to introduce cheap-talk communication in a laboratory multilateral bargaining setting, there are few studies that have explored the effects of communication in bilateral bargaining games. Extrapolating from these studies, one would expect more egalitarian outcomes and less proposer power in a bargaining game with communication in light of the results of the previous literature. However, our paper highlights the crucial difference between multilateral and bilateral bargaining games. The presence of competition among bargainers for the place in the coalition, which is present in the multilateral bargaining and absent in bilateral bargaining, reverses the effects of communication and allows for a large reconciliation between theoretical predictions and experimental results. Indeed, in our experiment, non-proposers obtain smaller shares when communication is allowed, while proposers take advantage of the competition between non-proposers to extract a near-equilibrium share of resources. In other words, we observe less egalitarian and more unequal split of resources in the presence of communication.

The importance of our findings extends well beyond experimental work and has direct implications for bargaining processes (legislative or other) outside the laboratory. Our results suggest that communication can be used as a tool to moderate or enhance proposer power. For instance, if one's goal is to ensure more egalitarian distributions of resources, then one would try to reduce the communication between legislators in order to prevent competition among non-proposers.

\subsection{Communication in Bargaining Experiments}

While the literature on the effects of pre-play communication in various strategic setups is vast, there are surprisingly few studies that look at effects of cheap-talk communication in a bargaining framework. Here we review the two most closely related to our paper studies, both of which focus on bilateral as opposed to multilateral bargaining. ${ }^{6}$

\footnotetext{
${ }^{6}$ See also Bolton, Chatterjee and Valley (2003) and Diermeier, Swaab, Medvec, and Kern (2008) who study effects of communication in three-person coalition negotiation experiments. Their setup is quite different from ours in various respects. In particular, subjects choose between pre-specified budget allocations in which the total amount of resources to be distributed depends on the number and identity of the coalition partners. Moreover, there is no proposer per se and, hence, no proposer power to
} 
The first study is Roth (1995) who focuses on the ultimatum game and compares frequencies of disagreements and distribution of resources in three treatments: (1) a baseline treatment in which subjects could not communicate with each other, (2) a treatment in which subjects were asked to discuss the game with each other face-to-face prior to making their decisions and (3) a treatment in which subjects were asked to converse but were restricted to social conversations. ${ }^{7}$ In this experiment, communication has two significant results. First, communication decreases the frequency of disagreements, which are measured by the number of rejected proposals. Second, communication increases the share of the responder and overall leads to a more equal distribution of resources between the proposer and the responder.

The second study is Andreoni and Rao (2011) who investigate the effects of pre-play communication in the dictator game. The authors alter who in a pair can speak and whether or not the person receiving a message can respond. The authors find that the fraction of resources kept by the allocator crucially depends on whether the receiver is allowed to speak. Generally, they find that if the receiver sends a message to the allocator, he receives a higher share from him, so that communication allows for more egalitarian distributions. $^{8}$

The message that emerges from these two studies is that allowing bargainers to communicate reduces proposer power and makes the final allocations more egalitarian and less unequal. The question we will address in this paper is whether this pattern extends to a multilateral setup in which proposals are accepted or rejected by a majority voting rule. Moreover, our setup provides the most natural communication environment, in which bargainers will be able to exchange messages freely with each other through chat boxes. This design is necessary to draw conclusions about the effects of communication per se rather than other non-verbal factors such as facial cues, head movements and others that are present in face-to-face communication and known to affect bargaining results.

investigate. Nonetheless, these experiments show that the type of communication (face-to-face, via a computer, with private rooms among others) affect the number of subjects included in the coalition.

${ }^{7}$ In this "social communication treatment subjects were asked to learn each others first name and year in school and were not allowed to discuss the bargaining game.

${ }^{8}$ In three out of four treatments in Experiment 1, in which the receiver had an opportunity either to send a verbal message to the allocator or respond to the message received from the allocator, the allocator eventually kept smaller fraction of resources than in the baseline treatment with no communication. In the baseline treatment, the allocator keeps on average $\$ 8.5$ while he keeps $\$ 7.0-\$ 7.6$ when the receiver can speak depending on the order of messages. However, in the treatment, in which the allocator sends a written verbal message along with the decision and the receiver remains silent, the allocator keeps on average $\$ 9.4$ which is significantly more than in the baseline treatment. 
The remainder of the paper is organized as follows. The theory is in Section 2. The experimental design can be found in Section 1. Our results are in Section 4. Concluding remarks are in Section 5.

\section{Theoretical Model and Predictions}

As a base for our experiment, we use the classical model of multilateral bargaining of Baron-Ferejohn (1989). A legislature consists of $N$ (odd) members (each representing a legislative district), a recognition rule that determines the standing proposal in each round of the bargaining session, an amendment rule and a voting rule. The legislature allocates a fixed budget $X$ of divisible benefits among its members using a majority rule with no side payments. Members of the legislature are risk-neutral and have conflicting preferences: each member prefers a higher share of the resources allocated to his district and does not care about the other districts. In other words, members of the legislature have preferences that depend only on the benefits allocated to their district.

The bargaining period consists of possibly several rounds. At the beginning of the first round, one member of the legislature is recognized to make a proposal. Each member $i$ has the same probability of being recognized as a proposer $p_{i}=\frac{1}{N}$. The proposer $i$ submits a proposal $x=\left(x_{1}^{i}, \ldots, x_{N}^{i}\right)$, where $x_{j}^{i}$ is the share of member $j$ in the proposal submitted by member $i$. To be valid, a proposal must satisfy the budget constraint $\sum_{j=1}^{N} x_{j}^{i} \leq X$

This proposal is called the motion on the floor. Under the closed amendment rule, the rule we consider in this paper, the motion on the floor is immediately voted on by the members of the legislature. ${ }^{9}$ If the proposal is approved by the majority of votes, then the legislature adjourns. If it is rejected, then the budget shrinks by a factor of $\delta$, the legislature moves to the next bargaining round, and the process repeats itself (a (possibly) new proposer is chosen at random etc.) until a proposed distribution receives a majority of votes. The discount factor $\delta$ can be thought of as representing the cost of delay in reaching an agreement.

\footnotetext{
${ }^{9}$ See Frechette-Kagel-Lehrer (2003) for a comparison of the bargaining outcomes under closed and open amendment rules. Under the open amendment rule, after the proposer submits the motion to the floor, another member of the legislature is selected to either amend the proposal or move the previous question for the vote. If the proposed allocation is approved then the legislature adjourns, otherwise, the legislature moves to the next bargaining session and the process repeats itself until the proposed allocation is approved.
} 
In the experiments we use the following parameterization: the legislature consists of $N=5$ members, the initial budget is 250 tokens and the common discount factor is $\delta=0.8$.

Following the tradition in the literature, in order to avoid multiplicity of the subgame perfect Nash Equilibria, we will restrict our attention to the stationary subgame perfect Nash equilibria (SSPE). There exists a unique SSPE in this game, in which a proposer receives the highest share of resources (170 out of 250 tokens) and forms a minimum winning coalition that consists of three members including himself. The two other coalition members each receive 40 tokens, while the non-coalition members receive nothing. This proposal is passed with no delay by three "yes" votes: one from the proposer himself and one from each of the coalition partners. The shares of coalition partners are just equal to the expected value of rejecting the proposed allocation, which takes into account several factors: the shrinking of the available resources, the possibility of becoming a proposer in the next bargaining session and the possibility of being excluded from the future coalition.

In this paper we also consider an extended version of Baron-Ferejohn model described above, in which the only modification is the addition of a cheap-talk communication stage between members of the legislature. More precisely, after one member is recognized as a proposer and before he/she submits motion to the floor, all members of legislature can engage in a negotiation process. Communication is unrestricted cheap-talk and any member can send any number of messages to any subset of the members in the legislature. In other words, members can exchange both private and public messages between each other.

The stationarity refinement of the subgame perfect Nash equilibrium guarantees that the extended version of the bargaining game has a unique SSPE which is identical to the SSPE in the bargaining game with no communication. To understand the intuition of this result further recall the definition of stationarity:

"an equilibrium is said to be stationary if the continuation values for each structurally equivalent subgame are the same." (Baron-Ferejohn (1989), page 1191)

The stationarity restricts the equilibrium strategies to be time independent and anonymous. The continuation value of all members remains the same as in the game with no communication because the cheap-talk communication is non-binding. Consider, for in- 
stance, a non-proposer who during the negotiation stage indicates to a proposer that he is willing to accept an amount smaller than the one prescribed by the SSPE (which is 40 tokens in our parameterization). This promise will not be followed through at the voting stage, since a non-proposer will always reject the motion that gives him less than the continuation value of the game. Therefore, there is no opportunity for a non-proposer to ensure a place in the coalition by indicating to a proposer that he is "cheaper" than other members. Thus, as before, the optimal allocation is the one in which the proposer forms minimum winning coalition with two other random members and gives coalition partners 40 tokens which is just equal to the expected value of rejecting the proposed allocation (their continuation value).

\section{Experimental Design}

All the experiments were conducted at the California Social Sciences Experimental Laboratory (CASSEL) at UCLA. We ran three different treatments, in which a total of 235 subjects participated. The subjects were recruited from the general undergraduate population of UCLA and no subject participated in more than one experimental session. All the interactions between participants were performed through the computer terminals. Instructions for the Chat treatment can be found in Appendix A and all other treatment instructions are available upon request.

In all treatments we implemented the Baron-Ferejohn bargaining protocol described in Section 2. We start by describing the specifics of the Baseline treatment. In this treatment subjects participated in a series of 15 bargaining sessions. Before the beginning of each bargaining session, subjects were randomly divided into groups of 5 members and each was randomly assigned an ID number. Each of these groups represents a legislature with $N=5$ members. A group's task is to divide a fixed budget of 250 tokens among its members. At the beginning of each bargaining session, one of the five members is randomly chosen to be the proposer. His assigned ID number is revealed to the entire group. The proposer proposes an allocation that is observed by all members of the group, with shares to each member clearly indicated. After that, all members of the group including the proposer are asked to vote to accept or reject the proposed allocation. If the allocation receives three or more votes then it passes and the bargaining session is over. If the allocation receives fewer than three votes, then the budget shrinks by the discount 
factor $\delta=80 \%$ and the bargaining continues with a random selection of a (possibly) new proposer from the same group. This process repeats itself until a proposer's allocation gets the majority of votes and passes. After each bargaining session subjects are randomly re-matched to form new groups of 5 voters each and are assigned new ID numbers. We used random matching between bargaining sessions to implement the one-shot bargaining game we are interested in exploring in this paper. At the end of the experiment, we sum up all the tokens earned by each subject in all bargaining sessions and convert them to the US dollars using the rate 50 tokens $=\$ 1 .^{10}$

The Chat treatment was similar to the Baseline treatment except for one feature. After the proposer was determined and his ID number revealed to the group members, but before the proposer submitted his proposal, members of the group could communicate with each other using a chat tool. This chat tool allowed subjects to send any message they wanted to any subset of members in their group. For instance, members could send private messages that would be delivered only to a particular member or to a subset of members, and they could also send public messages that would be observed by all members of the group. The duration of the communication was in the hands of the proposer: the chat tool was disabled when the proposer submitted his proposal for a vote. All the messages sent by subjects during the communication stage were recorded.

\begin{tabular}{lcccc}
\hline \hline Treatment & Communication & $\begin{array}{c}\text { \# of Experimental } \\
\text { Sessions }\end{array}$ & $\begin{array}{c}\text { \# of Bargaining } \\
\text { Sessions }\end{array}$ & Total Subjects \\
\hline Baseline & No & 3 & 15 & 95 \\
Baseline Long & No & 1 & 30 & 30 \\
Chat & Yes & 3 & 15 & 110 \\
\hline \hline
\end{tabular}

Table 1: Experimental Design

Our final treatment, Baseline Long treatment, was identical to the Baseline treatment except that subjects participated in a series of 30 bargaining sessions. We conducted this treatment to inspect whether communication serves simply to accelerate learning.

\footnotetext{
${ }^{10}$ Our Baseline treatment is identical to Experiment 1 in Frechette-Kagel-Lehrer (2003) except for two features. First, FKL uses fixed group matching, while we implement random matching between bargaining sessions to replicate a one-shot game and avoid repeated game effects. Second, in FKL, at the beginning of each bargaining session before the identity of a proposer is determined, each voter proposes how to divide a budget. This is done to maximize the number of observations one obtains from the experiment. In our design, the identity of the proposer is determined first, and then only the proposer submits an allocation. This structure of the game is necessary for the treatment with communication, and, thus, we kept it the same in all treatments for consistency purpose.
} 
Table 1 summarizes the details of all our experiments.

\section{Results}

We report the results of our experiments in the following order. First, we explore whether introducing unrestricted communication changes the bargaining outcome of the game. To answer this question we compare the Baseline and the Chat treatments. Second, we show that communication can't be replaced by repetition of the game. We do this by comparing the results of the Chat and the Baseline Long treatments. Finally, we turn to the communication specifically to uncover the mechanism through which communication affects the bargaining process. ${ }^{11}$

Result 1: The impact of unrestricted communication. Proposers extract a significantly higher share of resources when unrestricted communication is allowed. Overall, the sessions with unrestricted communication show much closer conformity to the SSPE predictions than the sessions without communication.

One of the most robust phenomena observed in the experimental bargaining literature is the failure of the proposer to extract equilibrium rents. While proposers receive a larger share of the benefits than coalition members, these shares are often more than $40 \%$ smaller than the SSPE prediction. ${ }^{12}$ Further, while experience and repetition slightly increases proposer shares, the gap between what had been observed in laboratory experiments and what is theoretically predicted remained large by the end of the experiment. This is a fact that has been noted in prior work and that we will revisit when we discuss the Baseline Long treatment. ${ }^{13}$.

\footnotetext{
${ }^{11}$ We present our results using the last five bargaining sessions of the experiment. The qualitative results are not sensitive to using more or fewer bargaining sessions in the analysis but we restrict our analysis to the last five so that the learning of the game has largely taken place.

${ }^{12}$ Frechette-Kagel-Lehrer (2003) report that in the last 5 rounds of the experiment, proposers take between $\$ 9$ and $\$ 10$ out of total of $\$ 25$, while the equilibrium predicts that their share should be $\$ 17$.

${ }^{13}$ For example, in Experiment 2 of Frechette-Kagel-Lehrer (2003), the authors attempt to speed up the learning process by increasing the number of bargaining sessions from 15 to 25 and by introducing a sixth legislator, an economics graduate student, who was instructed to make proposals and to vote according to a pre-specified computer algorithm. This computer algorithm involved proposing a higher shares to a proposer than the ones observed in the baseline experiments and approving only the proposals that gave her a share at least as large as the SSPE. Even in this modified version of the game, the authors observe that proposers' share are still way below the SSPE predicted ones: in the last 3 bargaining
} 
Figures 1(a)-1(b) present the histograms and the cumulative distribution of the proposer's share in the last 5 bargaining sessions in the Baseline and the Chat treatments for those proposals that passed without delay. Figure 1(d) depicts the evolution of the proposer's share as subjects gain more experience with the game. ${ }^{14}$

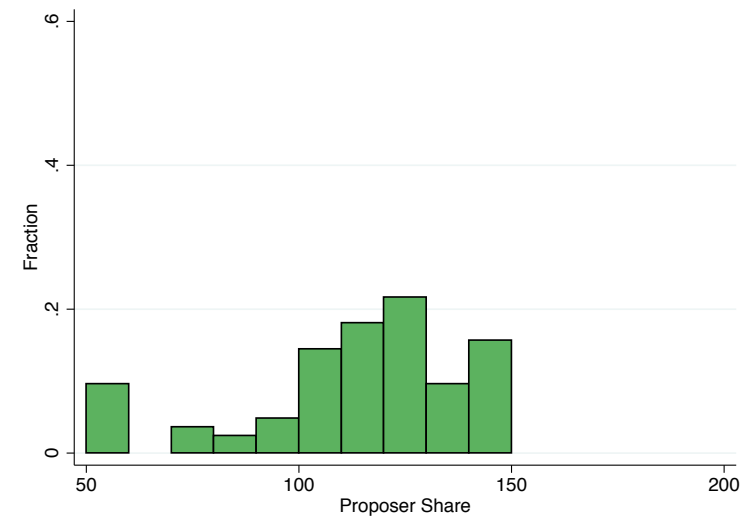

(a) Baseline: Histogram of Proposer's Share

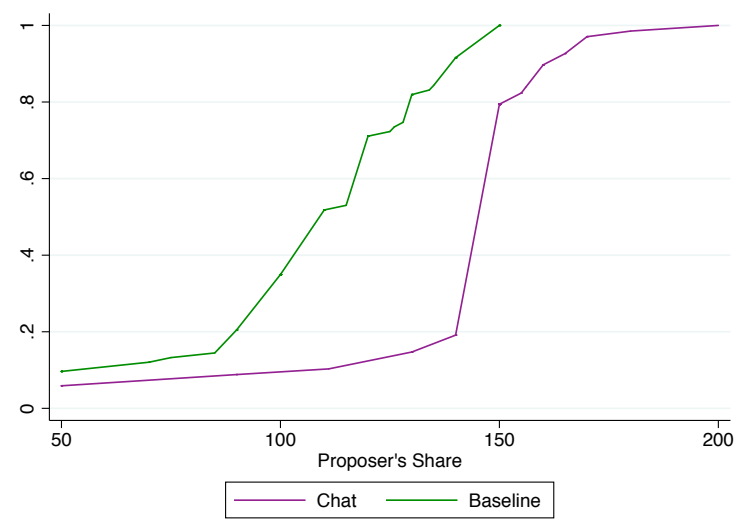

(c) Cumulative Distributions

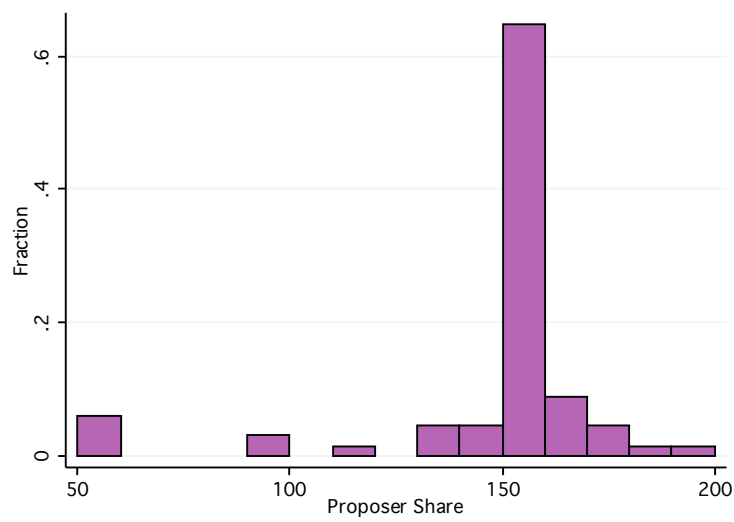

(b) Chat: Histogram of Proposer's Share

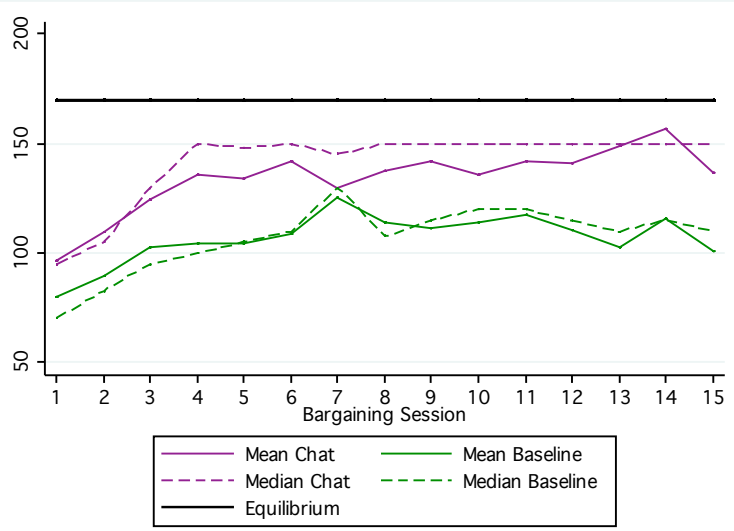

(d) Dynamics of Proposer's Share

Figure 1: Proposer's Share in the last 5 bargaining sessions (proposals that passed without delay)

The increase in the proposer's share when communication is allowed is significant. In the last five bargaining sessions, in the Baseline treatment, proposers receive on average sessions proposers receive on average $\$ 12$ instead of $\$ 17$. This average of $\$ 12$ is likely to be driven by the computer allocating $\$ 15$ to a proposer and $\$ 5$ to two coalition members, while human proposers have never allocated such a high share to themselves. In the Equal Weights treatment in Frechette-KagelMorelli (2005) the authors report that experienced subjects take on average $40.3 \%$ and inexperienced ones take $39.3 \%$ of the available resources for themselves, while the Baron-Ferejohn model predicts that this fraction should be $60 \%$.

${ }^{14}$ We focus here on the proposals that passed with no delay in order to remove any reputation concerns that would appear if the bargaining covered two more stages. Looking instead at all proposals (regardless of delays) does not change the results: proposers in the Chat treatment extract a share significantly higher than when communication is not allowed even when there are delays. These results are available upon request. 
110 tokens. In the Chat treatment, this average share is 144 tokens, more than $30 \%$ higher. The null hypothesis that proposers receive the same amount in the Baseline and the Chat treatments in the last 5 bargaining sessions is rejected at the $1 \%$ level with a Wilcoxon Ranksum test. ${ }^{15}$ Figure $1(\mathrm{~d})$ shows that while in both Baseline and the Chat treatments proposers' shares grow with experience, in every single bargaining session the rents extracted by the proposers are higher when communication is allowed. ${ }^{16}$

\begin{tabular}{lccc}
\hline \hline & Baseline & Chat & $\begin{array}{c}\text { Baseline } \\
\text { Long }\end{array}$ \\
\hline Delays & & & \\
Proposals passed with no delay (all bargaining sessions) & $81 \%$ & $89 \%$ & $80 \%$ \\
Proposals passed with no delay (first 5) & $87 \%$ & $90 \%$ & $87 \%$ \\
Proposals passed with no delay (last 5) & $87 \%$ & $85 \%$ & $73 \%$ \\
\hline Distribution of Resources & & & \\
All proposals & $72 \%$ & $87 \%$ & $72 \%$ \\
\hline Double Zero strategy & $7 \%$ & $5 \%$ & $6 \%$ \\
Single Zero strategy & $17 \%$ & $5 \%$ & $18 \%$ \\
Equal Split strategy & & & \\
Proposals that passed with no delay (first 5) & $66 \%$ & $83 \%$ & $62 \%$ \\
\hline Double Zero strategy & $7 \%$ & $7 \%$ & $15 \%$ \\
Single Zero strategy & $22 \%$ & $6 \%$ & $19 \%$ \\
Equal Split strategy & \multicolumn{3}{c}{} \\
Proposals that passed with no delay (last 5) & $78 \%$ & $90 \%$ & $73 \%$ \\
\hline Double Zero strategy & $2 \%$ & $3 \%$ & $5 \%$ \\
Single Zero strategy & $14 \%$ & $6 \%$ & $18 \%$ \\
Equal Split strategy & &
\end{tabular}

Table 2: Frequency of Delays and Distribution of Resources in all Treatments

We summarize the other characteristics of the bargaining process with and without communication in Table 2. In this table we report the frequency of delays as well as how the proposers distribute the resources between the voters in all three treatments. The first two columns show the outcomes of the Baseline and the Chat treatments.

Delays are rare with or without communication: more than $85 \%$ of the proposals in the last 5 bargaining sessions are accepted without delays in both treatments. The

\footnotetext{
${ }^{15}$ The unit of observation is proposer's share (average per subject) in the last 5 bargaining sessions for those proposals that passed with no delay. The results are unchanged if we analyse the data at the session level, where the unit of observation is the average proposer share in each session.

${ }^{16}$ A series of Wilcoxon Ranksum tests show that in twelve out of fifteen bargaining sessions (all but bargaining sessions 1,2 and 7), the proposers' shares are significantly higher in the Chat than in the Baseline with a significance of at least $5 \%$.
} 
acceptance rate of proposals isn't significantly different between these two treatments. ${ }^{17}$

To compare the distribution of resources between treatments we will use the convention introduced in Frechette, Kagel and Lehrer (FKL) (2003). FKL define three mutually exclusive types of allocations: (1) the Double Zero strategy allocation, in which the sum of two lowest shares is less or equal to 20 tokens, (2) the Single Zero strategy allocation, in which four members receive more than 10 tokens and the lowest share is less or equal to 10 tokens, and (3) the Equal Split strategy allocation, in which each share is at least 40 tokens. Interestingly, over $90 \%$ of all strategies can be categorized into one of these three strategies. Recall that according to the SSPE prediction, only three voters (including the proposer) receive positive shares and the two remaining voters get nothing. In other words, since the proposals are passed or rejected using a majority rule, we expect minimum wining coalitions of three voters to emerge and, thus, the Double Zero strategy to be the most prevalent among the strategies described above.

This is precisely what we observe in the experimental data. In both treatments, a majority of the proposers form minimum winning coalitions by allocating resources to themselves and two other members of their group. This happens in $72 \%$ of all proposals submitted in the Baseline treatment and in $87 \%$ of all proposals submitted in the Chat treatment. By the last five bargaining sessions, these fractions are $78 \%$ and $90 \%$ and are not significantly different. ${ }^{18,19}$ In the Chat treatment, among the proposals that passed with no delay in the last 5 bargaining sessions, $89 \%$ of subjects always use the Double Zero strategy when they are selected to be proposers and $5 \%$ never do it, compared with $63 \%$ and $22 \%$ in the Baseline treatment, respectively.

Supermajorities, that is situations in which proposers give positive shares to four out of five members of the group, or in other words Single Zero strategies, are rare in both treatments (7\% and 5\% in the Baseline and Chat treatments, respectively). We observe more equal-split distributions in the Baseline treatment (17\% of all proposals) compared with the Chat treatment (5\% of all proposals). Further, $21 \%$ of subjects have, at one

\footnotetext{
${ }^{17}$ The p-value of a Test of Proportions is greater than $10 \%$, whether we use session-level data or the acceptance rate of each proposal on the floorf.

${ }^{18}$ Given that some categories have very few observation, we perform a Fischer Exact Test where the unit of observation is, for each subject, the fraction of times he employed Double Zero strategy over the time period considered. We find that $p=0.089$ if we consider all periods, and $p>.10$ if we consider only the last five periods).

${ }^{19}$ This difference may be due to the fact that in the Chat treatment, some voters may "educate" proposers to the fact that they only need three votes and so the fraction of Double Zero strategies is high right from the beginning of the experiment while participants in the Baseline treatment may take some time to learn.
} 
point or another, used the Equal-Split strategy in the Baseline treatment, while this fraction is below $12 \%$ for the Chat treatment. ${ }^{20}$

Our results from the Baseline treatment are consistent with the prior literature. ${ }^{21}$

Result 2: Learning through repetition versus communication. Increasing the number of repetitions of the game does not help subjects converge to the SSPE predictions even after they play the game many (30) times: repetition is not a substitute for communication.

We have seen that introducing unrestricted communication has a significant impact on the bargaining process. Indeed, in the Chat treatment we observe bargaining outcomes that are close to the SSPE predictions. In this section, we will investigate whether learning through repetition (the standard way in which most of the experimental literature asserts learning) has similar effects on bargaining outcomes. In order to do that, we will compare the Baseline Long treatment with the Baseline treatment and the Chat treatment.

Table 2 shows that the Baseline Long treatment is similar to the Baseline treatment in terms of strategies used by the proposers and the frequencies of delays. Indeed, there is no statistical difference in the amount of delays, the fraction of minimum winning coalitions and fraction of equal splits between the Baseline and Baseline Long treatments ( $\mathrm{p}$-value $>0.10)$. However, the bargaining outcomes in the Baseline Long treatment are starkly different from those in the Chat treatment. The fraction of delays, as well as the fraction of minimum winning coalitions and equal split strategies are significantly different between the Chat and Baseline Long treatments. ${ }^{22}$

\footnotetext{
${ }^{20}$ The p-value of a Fisher Exact Test where the unit of observation is, for each subject, the fraction of proposals that are Equal-Split is $p=0.063$.

${ }^{21}$ Similarly to our results, FKL (2003) document that delays are rare and that the most prevalent strategy used by the proposers is the Double Zero strategy (occurring $68 \%$ of the time in the last 5 bargaining sessions). In addition, FKL find that Equal Splits strategy occur $29 \%$ of the time in the last 5 bargaining sessions. One reason that FKL observe a higher fraction of equal splits and a slightly lower fraction of delays is that they employed a fixed matching protocol. Fixed matching generates repeated game effects between voters, and subjects might be more inclined to reciprocate to their group members by dividing resources equally if they know they will be meeting the same voters in all bargaining sessions. In all our experiments subjects were randomly and anonymously rematched to form new groups of 5 voters in each bargaining session, so as to implement the one-shot bargaining game that is modeled by the theory.

${ }^{22}$ The p-values for Fisher Exact Tests using the fraction of time that each individual uses those strategies as a unit of observation are all strictly less than 0.01 .
} 


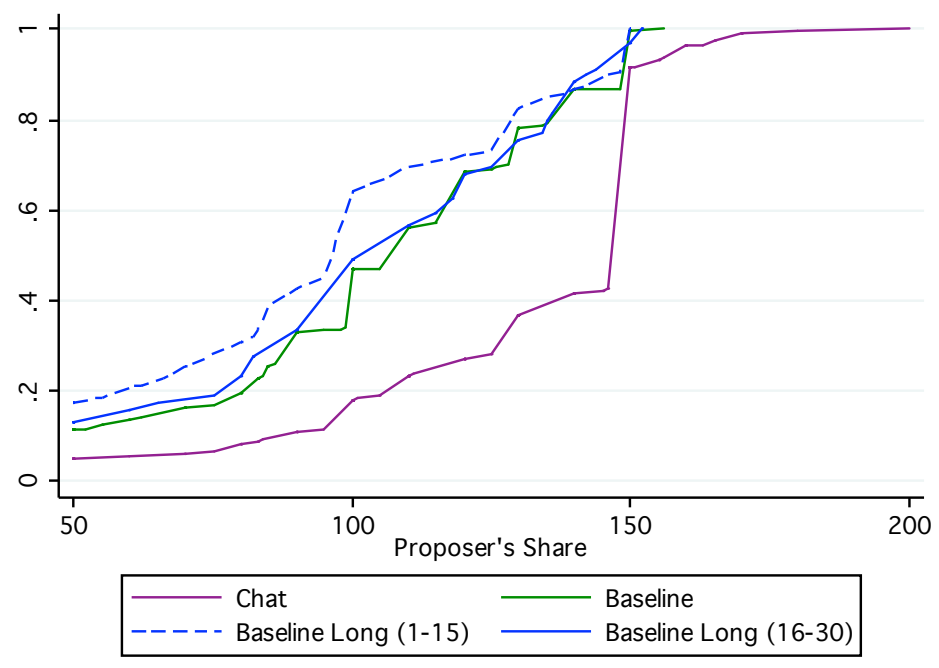

Figure 2: Cumulative distribution of Proposer shares in the Baseline, Chat and Baseline Long treatments (proposals that passed without delay).

Perhaps more surprisingly, allowing subjects to play more repetitions of the game does not increase the power of the proposer. Figure 2 presents the cumulative distributions of the shares of the proposer in the Baseline, Chat and Baseline Long treatments. In fact, the mean (median) share of the proposer in the proposals that passed without delay in the Baseline Long treatment in the last 15 bargaining sessions is 105 (110) tokens, which is similar to 106 (110) tokens in the Baseline treatment and significantly smaller than 133 (150) tokens in the Chat treatment. These results are confirmed by statistical analysis. $^{23,24}$

In the remainder of the analysis we will focus on the Chat treatment specifically. We will analyze the chat messages that the members of the legislature send to each other to uncover the mechanism through which communication affects bargaining outcomes.

\footnotetext{
${ }^{23}$ Wilcoxon Ranksum and Kolmogorov-Smirnoff tests show that the median and distribution of proposers' shares in the Baseline and Baseline Long treatments are not statistically different ( $\mathrm{p}$-value $>0.10$ ). The statistical comparison between the Baseline Long and the Chat treatment, however, shows that these two treatments result in significantly different outcomes for proposers ( $\mathrm{p}$-value $<0.01$ ).

${ }^{24}$ The findings concerning the Baseline Long and Baseline treatments are in line with the previous literature (see FKL (2003) and Footnote 13).
} 
Result 3: Communication as a tool to reduce uncertainty for the proposers. By communicating their reservation prices to the proposer, voters reduce the uncertainty the proposer faces.

The experimental literature on bargaining games with no communication attributes the failure of the proposer to obtain the large shares predicted by the theory to the reluctance of at least some coalition partners to accept small shares. Indeed, when voters are offered shares close to the predicted ones, they often reject them. This forces the proposers to reduce their own shares in order to offer higher amounts to the votes and secure enough "yes" votes for the proposal to pass. McKelvey (1991), Frechette-Kagel-Lehrer (2003), Diermeier-Morton (2004), Frechette-Kagel-Morelli (2005a), Frechette-Kagel-Morelli (2005b), and Frechette-Kagel-Morelli (2011) document this phenomenon in multilateral bargaining environments, and Roth (1995) surveys a large body of experimental data from alternating-offer bilateral bargaining experiments that exhibit similar patterns. FrechetteKagel-Morelli (2005) suggest that what drives the proposers to offer coalition partners higher shares is the heterogeneity between subjects rather than the average behavior :

... in this case it is not so much what the average base player is willing to accept that is responsible (because the average willingness to accept is reasonably close to the SSPE prediction). Rather, it is the between subject variation in what base players are willing to accept that is responsible, so that to maximize expected income, formateurs need to offer substantially more than the SSPE share or else face very high rejection rates. (Frechette-Kagel-Morelli (2005))

By providing a channel for the non-proposer to signal to the proposer the amount he/she is willing to accept, communication may solve the uncertainty problem that the proposer faces. This explains why proposers are able to extract a significantly larger share of resources in the game with communication.

We start by noting that in the Chat treatment, subjects indeed used the messaging system in almost every bargaining session (in $94 \%$ overall and in $97 \%$ of the last 5 bargaining sessions). A vast majority of the conversations included discussions about the game being played (92\% of the conversations in all bargaining sessions and $99 \%$ in the last 5 bargaining sessions). ${ }^{25}$ Further, in most of the conversations, at least one voter

\footnotetext{
${ }^{25}$ We used a broad definition of what it means to talk about the game, which includes conversations
} 
revealed to the proposer the amount they were willing to accept at the voting stage. In fact, this was done in $82 \%$ of chats in all bargaining sessions and in $93 \%$ of chats in the last 5 bargaining sessions. Heretofore, we will refer to such amount as stated reservation prices.

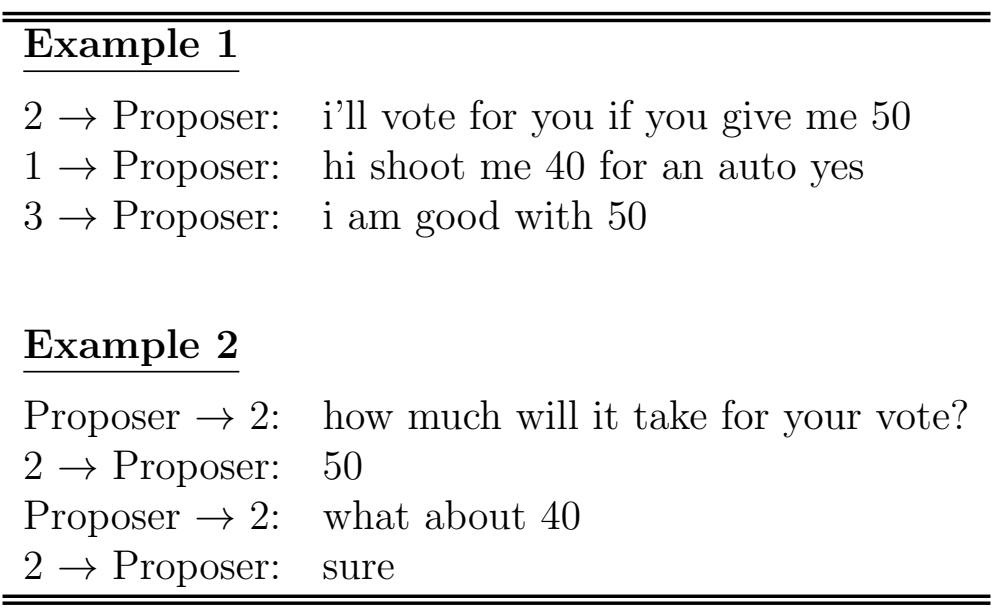

Table 3: Typical Conversations in the Chat treatment

Table 3 illustrates examples of the two most common types of conversations we observe. In both conversations non-proposers communicate their stated reservation price. In the first example, non-proposers initiate this conversation, while in the second example it is the proposer who solicits the reservation price of one of the members and then bargains it down. ${ }^{26}$

A noteworthy aspect of the data is that reservation prices are transmitted mostly through private rather than public chats. When voters chat about prices, fewer than $10 \%$ of these messages are sent to the entire group. In fact, almost $90 \%$ of conversations about price are bilateral and involve a non-proposer and the proposer communication. In other words, non-proposers and proposers discuss prices in one-on-one conversations: communication affects the distribution of resources through private (bilateral) conversations. So, even though public communication was allowed in this experiment, subjects opted not to use it.

about various strategies, the discussion of possible shrinking of the budget if the proposal is rejected, pleading to be in the coalition, requests for splits. There were, of course, over the course of the conversations, also messages that were not explicitly about the game, but that may have served to ingratiate oneself to the proposer. Many of these types of messages included jokes, such as "There are two cupcakes in an oven. The first says 'Boy its hot in here'. And the second says 'Hey look a talking muffin!"'

${ }^{26} 74 \%$ of all conversations about the reservation prices were initiated by non-proposers, while $26 \%$ were initiated by the proposers. In the cases where a non-proposer announces more than one price, we take the lowest one to be their reservation price. 
Figure 3 shows the histogram of stated reservation prices reported by the non-proposers at the communication stage in all bargaining sessions (Figure 3(a)) and in the last 5 bargaining sessions (Figure 3(b)). ${ }^{27}$ These figures show that reservation prices among voters are heterogeneous. While there is a noticeable peak at 50 tokens, some voters are willing to accept shares as low as 30 tokens, while others demand 75 tokens. This heterogeneity is reduced as subjects gain experience with the game but remains present even in the last 5 bargaining sessions.

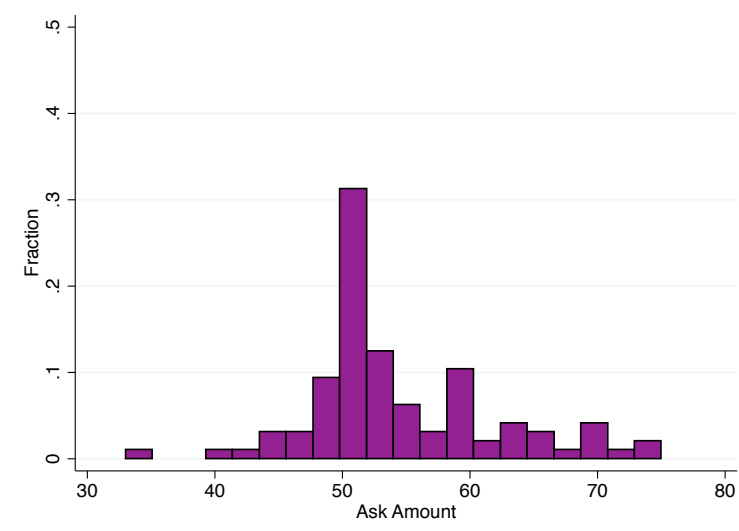

(a) Chat: all bargaining sessions

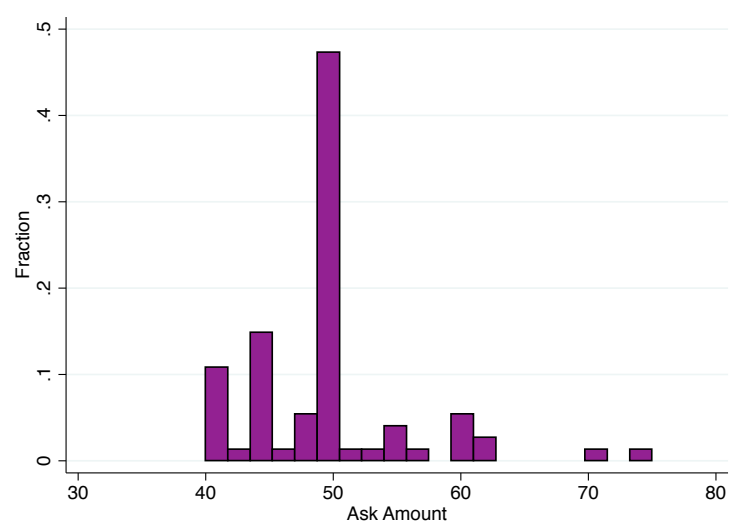

(b) Chat: last 5 bargaining sessions

Figure 3: Heterogeneity of Revealed Reservation Prices

The importance of the communication channel becomes clear: in the Chat treatment, the proposers can learn the amounts that voters are willing to accept. The only strategic consideration that is left for the proposers is to decide whether to trust the information offered by the voters (the question we turn to next). In the Baseline treatment the task of the proposer is significantly more complicated. Indeed, he has to form beliefs about the amounts that other members are willing to accept, and then determine the allocation that maximize his expected payoff given the risk that his proposal might be rejected.

One possible problem the proposers face is whether to trust the information they receive in the communication stage. Indeed, this is a cheap-talk stage in which no promises are binding. Table 4 illustrates that voters follow through on the promises they make in the communication stage. Overall, coalition partners accept offers that are at least as high as their stated price $96 \%$ of the time in all bargaining sessions. ${ }^{28}$ Subjects reject

\footnotetext{
${ }^{27}$ The unit of observation is the reported reservation price of a subject in a particular bargaining session.

${ }^{28}$ In half of the remaining $4 \%$ subjects who voted against a proposal that offered them at least what they asked for were in situations where the other non-proposer in the coalition received more than they did.
} 
shares that are lower than their stated price $72 \%$ of the time. ${ }^{29}$ As we will show in the next section, this happens predominantly in situations where the proposer is selecting two other (cheaper) members to be part of the coalition.

\begin{tabular}{lcccccc}
\hline \hline & \multicolumn{9}{c}{ proposed share } \\
& $0-29$ & $30-39$ & $40-49$ & $50-59$ & $\geq 60$ & Nb. Obs. \\
\hline$\underline{\text { Baseline }}$ & $2 \%$ & - & $67 \%$ & $84 \%$ & $97 \%$ & 1,130 \\
\hline$\underline{\text { Chat }}$ & $(0.45)$ & & $(0.06)$ & $(0.30)$ & $(0.19)$ & \\
$\begin{array}{l}\text { stated reservation price } \\
\leq \text { proposed share }\end{array}$ & - & - & $89 \%$ & $97 \%$ & $100 \%$ & \multirow{2}{*}{326} \\
\hline \hline
\end{tabular}

"-": fewer than 10 observations in this case

Table 4: Coalition Partners: Fraction of accepted share by share amount (in parenthesis: the share of proposals that are in those bins).

Table 4 also shows that acceptance rates are high and similar between the categories as long as the given share is equal or bigger than the declared one. Finally, consistent with the previous finding in the literature, while SSPE predicts that in the Baseline treatment shares of 40 tokens should be always accepted by the coalition partners, this is clearly not the case as $33 \%$ of shares between 40 and 49 tokens are rejected. In fact, if we look at shares of exactly 40 , over $45 \%$ are rejected, while in the Chat treatment, this fraction is significantly lower at $26 \%$.

Result 4: Communication as a tool to compete for a place in the coalition. Non-proposers compete with each other for a place in the coalition by lowering their stated reservation price. The proposers select the cheapest members and invite them into the coalition.

Figure 4 shows the evolution of the average price of voters (the size of a bubble is in proportion to the number of observations in each category). The average price declines from just above 60 tokens in the first bargaining session to fewer than 50 tokens in the

\footnotetext{
${ }^{29}$ Interestingly, proposers do not lie to individual responders, by, for example, suggesting that other responders are willing to accept less.
} 
last bargaining session. ${ }^{30,31}$

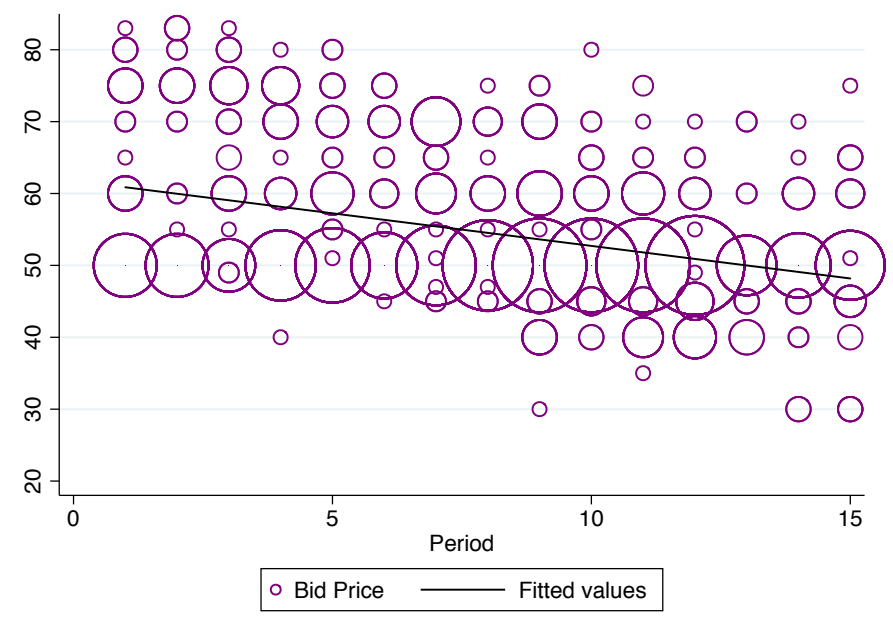

Figure 4: Evolution of Reservation Prices

There is a very clear incentive for responders to declare a low price: our data show that proposers invite the "cheapest" members of the legislature to the coalition. Indeed, out of the cases in which three or more voters revealed the amounts their are willing to accept to the proposer, the proposer chose two members with the lowest amounts in $97 \%$ of the cases in all bargaining sessions and in $100 \%$ in the last 5 bargaining sessions.

The second example in Table 3 is a clear example of how proposers are able to bargain with the responders. While not the predominant feature of the data, whether in response to a proposer or from their own volition, subjects lower their prices within a bargaining session in over $10 \%$ of the bargaining sessions and by an average of just above 12 tokens and a median of 10 tokens.

\begin{tabular}{l|ccc} 
& Coefficient & Robust Std. Err. & pvalue \\
\hline Reservation Price & $-0.013^{*}$ & 0.01 & 0.077 \\
Ranking of the Price & $-0.54^{* * *}$ & 0.10 & 0.000 \\
Constant & $2.11^{* * *}$ & 0.48 & 0.000 \\
\hline \hline
\end{tabular}

\# of Subjects: 99

\# of Observations: 537

${ }^{*}$ - significant at $10 \%^{* *}$ - significant at $5 \%^{* * *}$ - significant at $1 \%$

Table 5: Random effects probit regression ( $y_{i t}=1$ if one is offered at least 20 tokens).

Table 5 shows the results of a random effects Probit regression. The dependent vari-

\footnotetext{
${ }^{30}$ There were 2 outlier observations in which voters requested 10 tokens for a yes vote. We did not include them in the analysis.

${ }^{31}$ Regression analysis confirms that as subjects gain more experience with the game, the average price goes down: coefficient on the bargaining session counter is $\beta=-0.93$ and it is significant at the $1 \%$ level.
} 
able $y_{i t}$ is equal to 1 if one is invited into the coalition (i.e. offered more than 20 tokens). The independent variables are time dummies, ${ }^{32}$ the reservation price one declared, as well as what ranking that reservation price held (1 being the cheapest member, 2 the second cheapest, and so on). The higher the asking price, the less likely one is to be included in the coalition. In addition, the higher the ranking of that price, the less likely one is to be part of the coalition. In other words, both the absolute price as well as the relative price impact the probability of being part of the coalition: competition between responders matters.

\begin{tabular}{|c|c|c|c|}
\hline & Coefficient & Robust Std. Err. & pvalue \\
\hline Bargaining Session 2 & $10.35^{* * *}$ & 0.62 & 0.000 \\
\hline Bargaining Session 3 & $10.05^{* * *}$ & 2.96 & 0.001 \\
\hline Bargaining Session 4 & $9.14^{* * *}$ & 3.30 & 0.006 \\
\hline Bargaining Session 5 & $7.06^{* * *}$ & 0.94 & 0.000 \\
\hline Bargaining Session 6 & $5.50^{* *}$ & 2.18 & 0.012 \\
\hline Bargaining Session 7 & $4.51^{* * *}$ & 1.00 & 0.000 \\
\hline Bargaining Session 8 & $2.63^{* *}$ & 1.14 & 0.021 \\
\hline Bargaining Session 9 & $1.74^{*}$ & 1.02 & 0.087 \\
\hline Bargaining Session 10 & 0.28 & 1.96 & 0.888 \\
\hline Bargaining Session 11 & -0.43 & 2.22 & 0.846 \\
\hline Bargaining Session 12 & -1.78 & 1.63 & 0.274 \\
\hline Bargaining Session 13 & 0.95 & 0.75 & 0.204 \\
\hline Bargaining Session 14 & -0.33 & 1.26 & 0.796 \\
\hline Not Prev. in Coalition & $-1.03^{*}$ & 0.53 & 0.054 \\
\hline Constant & $50.18^{* * *}$ & 2.37 & 0.000 \\
\hline
\end{tabular}

Table 6: Random effects regression ( $y_{i t}$ is one's declared reservation prices).

In Table 6 we show the results of a random effects regression clustering at the session level. The dependent variable is the stated reservation price. The independent variables are a series of time dummies (where time is the recording of the number of periods one was a responder) as well as a dummy for whether a subject was in the coalition in the previous round. This is of particular relevance since proposers invite the cheapest members into the coalition. Thus, someone who was left out of the coalition in period $t-1$ may be pushed to lower his price in period $t$.

The results of the regression show that relative to the last bargaining session (Period 15), stated reservation prices in the earlier periods are significantly higher. The effect of

\footnotetext{
${ }^{32}$ None of the coefficients are significant and so they are not included in the output table.
} 
time, however, decelerates by the 10th period. The effect of not being included in the previous coalition is negative and significant with a p-value of 0.054 . In other words, a voter who was excluded from the coalition in the previous period responds by lowering the amount he is willing to accept in this period to increase his chances of getting into the coalition. To summarize, results of the regression analysis presented in Tables 5 and 6 support the hypothesis that communication increases competition between non-proposers for a place in the coalition, which allows proposer to extract higher share of resources.

\section{Conclusions}

In this paper we show that adding a cheap-talk communication stage in a standard legislative bargaining game leads to outcomes that are significantly closer to the SSPE predictions than any other experiment in this literature, where even experienced proposers fail to extract close to equilibrium rents. We extend the classical framework of BaronFerejohn to allow members of the legislature to communicate with one another through chat boxes after the proposer is selected and before he/she submits her proposal for allocation of resources. The communication is unrestricted and members of legislature are free to send any message to any subset of members of their group.

We find that communication has a significant and large effect on the distribution of resources and allows proposers to extract a significantly higher share of resources, approaching the theoretically predicted one. Moreover, communication also increases the percentage of coalitions that are minimum-winning.

In analyzing the content of the chat messages, we dissect the mechanism through which communication affects bargaining outcomes. Non-proposers use the chat messages to communicate the amounts they are willing to accept to the proposer. These prices are trust-worthy: coalition partners accept offers that are least of equal values as ones they state during negotiations, while they reject offers that are lower. Proposers select the coalition partners with the smallest stated reservation prices. This, coupled with the fear of being left out of coalition, leads to a decrease in stated reservation prices as subjects gain experience with the game.

Many features that are present outside the laboratory are impossible to replicate in a experiment, while others are easily implemented. Our experiment has shown that letting subjects communicate in a Baron-Ferejohn multilateral bargaining game is sufficient to 
reconcile theory and experiment. This essential modification to an experimental protocol has brought us closer to understanding the legislative process and may prove extremely useful in future experimental work. 


\section{References}

Andreoni, J. and Rao, J.. 2011, The power of asking: How communication affects selfishness, empathy, and altruism, Journal of Public Economics 95, 513-520.

Banks, Jeffrey and John Duggan. 2000, A Bargaining Model of Collective Choice. The American Political Science Review Vol. 94, No. 1, pp. 73-88.

Baron, D.P. and Ferejohn, J.A.. 1989, Bargaining in legislatures, American Political Science Review 83(4), 1181-1206.

Battaglini, Marco, Nunnari, Salvatore and Thomas R. Palfrey. 2011. The dynamics of distributive politics. Economic Theory

Battaglini, Marco, Nunnari, Salvatore and Thomas R. Palfrey. 2012. Legislative Bargaining and the Dynamics of Public Investment. American Political Science Review Vol. 106, No.2.

Battaglini, Marco and Stephen Coate. 2007. Inefficiency in Legislative Policy-Making: A Dynamic Analysis. American Economic Review, Vol. 97, n. 1, March 2007, pp.118-149.

Battaglini, Marco and Stephen Coate. 2008. A Dynamic Theory of Public Spending, Taxation and Debt. American Economic Review v. 98, iss. 1, pp. 201-36.

Bolton, Gary, Chatterjee, Kalyan and Kathleen Valley. 2003. How Communication Links Influence Coalition Bargaining: A Laboratory Investigation, Management Science vol. 49 (5), pp. 583-598.

Diermeier, Daniel and Timothy Feddersen. 1998. Cohesion in legislatures and the Vote of Confidence procedure. American Political Science Review, 92(3), 611-621.

Diermeier, D., and Merlo, A.. 2000. Government turnover in parliamentary democracies. Journal of Economic Theory, 94, 46-79.

Diermeier, D. and Morton, R.. 2005. Proportionality versus Perfectness: Experiments in Majoritarian Bargaining, in Social Choice and Strategic Behavior: Essays in the Honor of Jeffrey S. Banks, ed. by David Austen-Smith and John Duggan. Berlin: Springer. Forthcoming.

Diermeier, D., R. Swaab, V. Medvec and M. Kern. 2008. The Micro-Dynamics of Coali- 
tion Formation. Political Research Quarterly 61(3), 484-501.

Drouvelis, Michalis, Montero, Maria and Martin Sefton. 2010. Gaining power through enlargement: Strategic foundations and experimental evidence. Games and Economic Behavior, 69 (2010), pp. 274-292.

Eraslan, H. and Merlo, A.. 2002. Majority Rule in a Stochastic Model of Bargaining. Journal of Economic Theory Elsevier, vol. 103(1), pages 31-48,

Frechette, G. R., Kagel, J. H. and Lehrer, S. F.. 2003. Bargaining in legislatures: An experimental investigation of open versus closed amendment rules, American Political Science Review 97(2), 221-232.

Frechette, G. R., Kagel, J. H. and Morelli, M.. 2005a. Behavioral identification in coalitional bargaining: An experimental analysis of demand bargaining and alternating offers, Econometrica 73(6), 1893-1938.

Frechette, G. R., Kagel, J. H. and Morelli, M.. 2005b. Nominal bargaining power, selection protocol and discounting in legislative bargaining, Journal of Public Economics 89(8), 1497-1517.

Kagel John, Hankyoung Sung and Eyal Winter. 2010. Veto power in committees: an experimental study, Experimental Economics, 13: pp. 167-188.

McKelvey, R.. 1991. An Experimental Test of a Stochastic Game Model of Committee Bargaining. In Contemporary Laboratory Research in Political Economy. Ann Arbor: University of Michigan Press.

Miller, Luis and Christoph Vanberg. 2013. Decision costs in legislative bargaining: an experimental study, Public Choice, 155(3), pp. 373-394.

Roth, Al. 1995. Bargaining Experiments. In Handbook of Experimental Economics. Princeton, NJ: Princeton University Press, 253348.

Tergiman, Chloe. 2013. Institution Design and Public Good Provision: An Experimental Study of the Vote of Confidence Procedure. Working Paper. 


\section{A Instructions for the Chat Treatment}

This is an experiment in the economics of decision making. The instructions are simple, and if you follow them carefully and make good decisions you may earn a CONSIDERABLE AMOUNT OF MONEY which will be PAID TO YOU IN CASH at the end of the experiment. The currency in this experiment is called tokens. All payoffs are denominated in this currency. The total amount of tokens you earn in the experiment will be converted into US dollars using the rate 50 Tokens $=\$ 1$. In addition, you will get a $\$ 5$ participation fee if you complete the experiment.

In this experiment you will act as voters. You will distribute funds between yourself and others in a series of Periods. In each Period you will be randomly divided into groups of 5 members each. Each group will decide how to split a sum of money. Proposals will be voted up or down (accepted or rejected) by majority rule. That is, once 3 out 5 voters approve a proposal, it passes. In any Period you will not know the identity of the subjects you are matched with and your group-members will not know your identity. In each Period you will have to decide how to divide 250 tokens among the 5 voters in your group. One of the 5 voters in your group will be randomly chosen to make a proposal of how to split 250 tokens among the 5 voters (provisional budget proposal). Each voter has the same chance of being selected to make a proposal. Allocations to each member must be between 0 and 250 tokens. All allocations must add up to 250 tokens. After the selected proposer has made his/her allocation, this proposal will be posted on your computer screens with the proposed allocation to you and the other voters clearly indicated. You will then have to decide whether to accept or reject the proposed allocation.

If the proposal passes (gets 3 or more votes), the proposed allocation is implemented and we will move on to the next Period. If the proposal is defeated (gets less than 3 votes), there will be a call for new proposals and the process will repeat itself. However, the amount of money to be divided will be reduced by $20 \%$ of the amount of money in the preceding Round and rounded to the nearest integer. Thus, if the proposal in Round 1 is rejected, the new proposal in Round 2 will involve splitting 200 tokens among the 5 voters. And if this new proposal is rejected in Round 2, then in round 3 you will be splitting 160 tokens. If the proposal in rejected in Round 3, then in Round 4 you will be splitting 128 tokens, etc This process will repeat itself until a proposed allocation is passed (gets 3 or more votes). 
To summarize, the steps of the process will work as follows:

1. One voter is randomly selected to make a proposal of how to split 250 tokens.

2. A vote is held (each member of the group votes to accept or reject the proposal of selected voter).

3. If 3 or more out of 5 voters accept it, then the proposal passes and the Period is over. If the proposal is rejected, then the money shrinks by $20 \%$, we move on to the next Round of this Period and a new voter is chosen to propose the split (each of the 5 voters in a group has equal chance of being chosen). The process repeats itself until a proposal of selected voter passes.

In each Period, you will be randomly re-matched into groups of 5 voters each. Each member of the group is assigned an ID number (from 1 to 5), which is displayed on the top of the screen. Once the Period is over, you will be randomly re-matched to form new groups of 5 voters each and you will be assigned a (potentially) NEW ID. Please make sure you know your ID number when making your decisions. Since ID numbers will be randomly assigned prior to the start of each Period, all voters are likely to have their ID numbers vary between Periods, and, thus, it is impossible to identify subjects using their ID numbers.

In each round, after one voter is selected to propose a split but before he/she submits his/her proposal, members of a group will have the opportunity to communicate with each other using the chat box. The communication is structured as follows. On the top of the screen, each member of the group will be told her ID number. You will also know the ID number of the voter who is currently selected to make a proposal. Below you will see a box, in which you will see all messages sent to either all members of your group or to you personally. You will not see the chat messages that are sent privately to other members. In the box below that one, you can type your own message and send it either to the entire group or to particular members of the group. To select subjects that will receive your message, simply click on the buttons that correspond to the ID numbers of the subjects who you want to receive this message and hit SEND. You can send message to all members of your group by clicking SELECT ALL button.

The chat option will be available until the selected voter submits her proposal. At this moment the chat option will be disabled. 
Remember that in each Period subjects are randomly matched into groups and ID numbers of the group-members are randomly assigned. Thus, your ID number is likely to vary from Period to Period, and, therefore, it is impossible to identify your groupmembers using your ID number.

At the conclusion of the experiment we will sum up all the tokens you earned in the experiment and convert this amount into US dollars using the conversion rate 50 tokens $=\$ 1$. In addition, you will receive a $\$ 5$ participation fee for completing the experiment.

You are not to reveal your (potential) earnings, nor are you to speak or communicate in any other way with any other subject while the experiment is in progress. This is important to the validity of the study and will be not tolerated.

We will now go slowly through one practice Period to familiarize you with the screen. After the practice Period is over, we will start the experiment, in which you will play 15 Periods for cash.

Review. Lets summarize the main points:

1. The experiment will consist of 15 Periods. There may be several Rounds in each Period.

2. Prior to each Period, you will be randomly divided into groups of 5 voters each. Each subject in a group will be assigned an ID number.

3. At the start of each Period, one subject in your group will be randomly selected to propose a split of 250 tokens between the five of you. Before he/she submits his/her proposal, members of the group can use the chat box to communicate with each other. You may send public messages that will be delivered to all members of your group as well private messages that will be delivered to members that you specify explicitly.

4. Proposals to each voter must be greater than or equal to 0 tokens.

5. If a simple majority accepts the proposal (3 or more voters), the Period ends.

6. If a simple majority rejects the proposal then a potentially new voter will be randomly selected to make a proposal in subsequent Round of a given Period.

7. The amount of money to be divided shrinks by $20 \%$ following each rejection of a proposal in a given Period. 